\title{
Pneumonitis in Adult Onset Still's Disease: Uncommon or Under Diagnosed?
}

\section{Pneumonite na Doença de Still do Adulto: Rara ou Subdiagnosticada?}

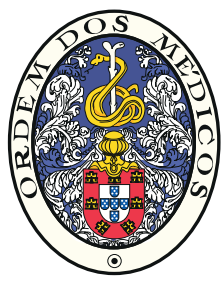

Sílvia FERNANDES $\triangle 1$ 1, Margarida ALMEIDA² ${ }^{2}$ José Alberto PEREIRA DA SILVA ${ }^{1}$, José Carlos ROMEU1 Acta Med Port 2017 Jul-Aug;30(7-8):578-581 - https://doi.org/10.20344/amp.7177

ABSTRACT

The adult onset Still's Disease is an uncommon entity characterized by multiple clinical manifestations. Pneumonitis, less often considered, deserves particular emphasis given the need for differential diagnosis and because it can progress to severe respiratory failure. With the aim to highlight the pulmonary parenchyma involvement in patients with adult onset Still's Disease, we present a case report which progresses with pneumonitis.

Keywords: Lung Diseases/etiology; Pneumonia/etiology; Still's Disease, Adult-Onset/complications

\section{RESUMO}

A doença de Still do adulto é uma entidade pouco comum que se caracteriza por manifestações clínicas muito variadas. A pneumonite, menos frequente, merece particular destaque dado a necessidade do seu diagnóstico diferencial e pela possível progressão para insuficiência respiratória grave. Com o objetivo de destacar a relevância do envolvimento do parênquima pulmonar na doença de Still do adulto, descrevemos um caso clinico que cursou com pneumonite.

Palavras-chave: Doença de Still de Início Tardio/complicações; Doenças do Pulmão/etiologia; Pneumonia/etiologia

\section{INTRODUCTION}

Adult onset Still's disease (AOSD), described by Bywaters in 1971, is an uncommon systemic inflammatory disease characterized by multiple clinical manifestations, with fever, evanescent rash and arthritis as the more frequent ones. ${ }^{1}$ Regarding laboratory tests, stands out leukocytosis with neutrophilia, increased erythrocyte sedimentation rate and serum ferritin levels. ${ }^{2}$ The prevalence of lung involvement varies according to the sample and the structure of the published studies, and pleuritis is the most common manifestation. ${ }^{3,4}$ Although less often considered, pneumonitis deserves particular emphasis given the need for differential diagnosis and because it can progress to severe respiratory failure. ${ }^{3}$

In order to highlight the importance of pulmonary parenchyma involvement in AOSD, we describe a case report that progresses with pneumonitis.

\section{CASE REPORT}

A 35-year-old black woman, Jehovah's witness, with previous diagnosis of unspecified hemoglobinopathy, presented with odynophagia, fever and evanescent mildly pruritic maculopapular skin rash in the upper and lower limbs, which disappeared during afebrile periods. One month after the beginning of the symptoms, she was treated with amoxicillin plus clavulanic acid. Due to maintenance of the symptoms, later associated with mild productive cough, with mucoid sputum, and myalgia she was admitted to the emergency room. Physical examination documented fever $\left(38.3^{\circ} \mathrm{C}\right)$, tachycardia $(108 \mathrm{bpm})$, hyperemic pharyngeal mucosa, mildly pruritic maculopapular skin rash and Koebner phenomenon detected in the trunk and extremities. Chest auscultation did not reveal any abnormal respiratory sounds. Regarding laboratory tests: hemoglobin $(\mathrm{Hb})$ - $10.4 \mathrm{~g} / \mathrm{dL}$; mean corpuscular volume - $68.9 \mathrm{fL}$; mean corpuscular hemoglobin - 21.8 pg; leucocyte count 25510/ $\mu \mathrm{L}$ with $88.2 \%$ neutrophil; aspartate aminotransferase - 58 $\mathrm{U} / \mathrm{L}$; lactate deshydrogenase - $869 \mathrm{U} / \mathrm{L}$ and C-reactiveprotein(CRP) - $25.3 \mathrm{mg} / \mathrm{dL}$. Chest radiography did not display any alterations. She was then admitted to the Hematology Department with the diagnosis of hemolytic crisis, which was not confirmed. Since infectious etiology was hypothesized, she started empirical antibiotic therapy. During hospitalization, and despite antibiotic escalation (ceftriaxone, meropenem), the patient maintained recurrent fever, even though no infectious agent was isolated. Furthermore, she presented polyarthritis, abdominal pain, generalized lymphadenopathy and decreased bibasal respiratory sounds but no adventitious breath sounds at chest auscultation. She maintained mild productive cough, with mucoid sputum. Chest radiograph was repeated revealing diffuse patchy infiltrates and small bilateral pleural effusion (Fig. 1). Abdominal ultrasound showed hepatosplenomegaly and a small amount of free peritoneal fluid. Computerized tomography (CT) scan documented densification with a mosaic pattern in the lung parenchyma, predominantly in the upper lobes, and moderate bilateral pleural effusion, conditioning passive atelectasis of the lower lobes (Fig.s 2A, 2B). It also showed generalized lymphadenopathy and hepatosplenomegaly. Bronchoscopy was performed, and the microbiological tests

\footnotetext{
1. Department of Rheumatology and Metabolic Bone Diseases. Hospital de Santa Maria. Centro Hospitalar Lisboa Norte. Lisbon. Portugal.

2. Department of Pathologic Anatomy. Hospital de Santa Maria. Centro Hospitalar Lisboa Norte. Lisbon. Portugal.

$\bowtie$ Autor correspondente: Sílvia Fernandes. Silvia_tfernandes@yahoo.com

Recebido: 10 de novembro de 2015 - Aceite: 13 de fevereiro de 2017 | Copyright $\odot$ Ordem dos Médicos 2017
} 


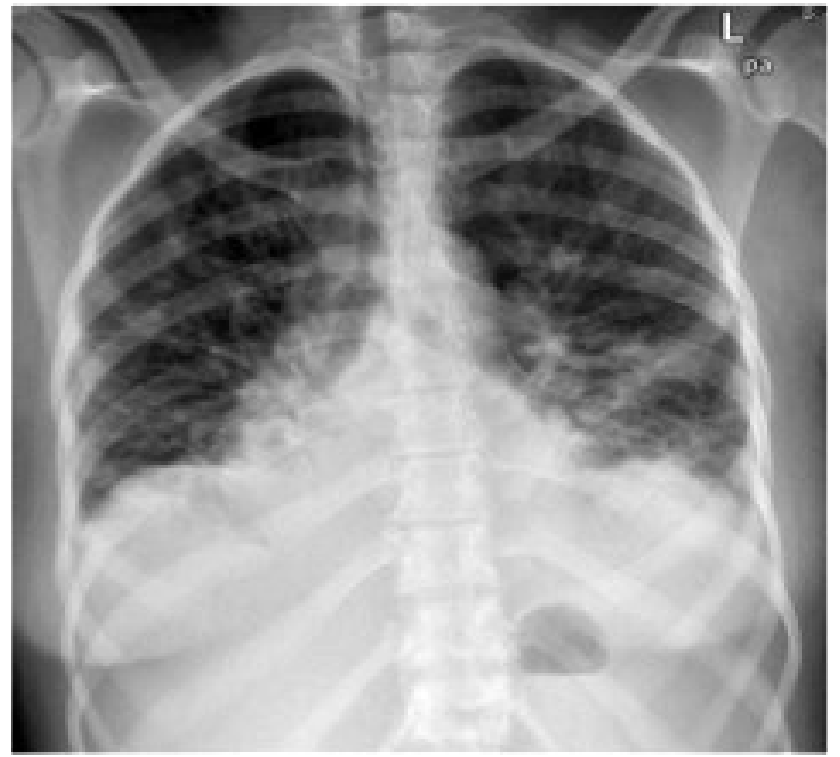

Figure 1 - Chest radiography - diffuse patchy infiltrates and small bilateral pleural effusion

of bronchial secretions and bronchoalveolar lavage were negative. Histopathological study revealed lung tissue with inflammation, pneumocytes hyperplasia and fibrosis (Fig. 3). Still stands out the negativity for other microbiological (blood and urine culture), serological tests, immunological tests, and tuberculin sensitivity test. Ferritin value was $2861.7 \mathrm{ng} / \mathrm{mL}$, the sickling test was positive, and the hemoglobin electrophoresis showed $33.1 \%$ hemoglobin $\mathrm{S}$ and $1.2 \%$ hemoglobin $\mathrm{F}$.

AOSD diagnosis was admitted, and the patient began therapeutics with prednisone (60 mg/day). Given the $\mathrm{Hb}$ value of $6.6 \mathrm{~g} / \mathrm{dL}$ and the refusal of the patient to perform erythrocyte concentrate transfusion, she was treated with darbepoetin and folic acid. At the fourth day of steroid therapy the patient was apyretic and progressive regression of the remaining disease manifestations was documented. Laboratory evolution was also favorable (Table 1). Chest CT scan, preformed two weeks later, displayed complete resolution of parenchymal and pleural abnormalities. After 28 days of hospitalization she was discharged for the outpatient clinic, remaining asymptomatic.

\section{DISCUSSION}

In the absence pathognomonic symptoms, signs or laboratory findings in AOSD, the diagnosis is based on clinical and laboratorial findings, and exclusion of other diseases. Our patient met the Yamaguchi major criteria (fever, arthralgia, typical rash, leukocytosis), four minor criteria (sore throat, lymphadenopathy and/or splenomegaly, liver dysfunction, and negative immunologic study) and rheumatic, infectious and neoplastic diseases were excluded or were very unlikely. ${ }^{5}$

The pulmonary manifestations in AOSD patients include pleurisy, acute or chronic pneumonitis and functional anomalies. ${ }^{3}$ However, pulmonary complications that threaten the patient's life, such as the syndrome of acute
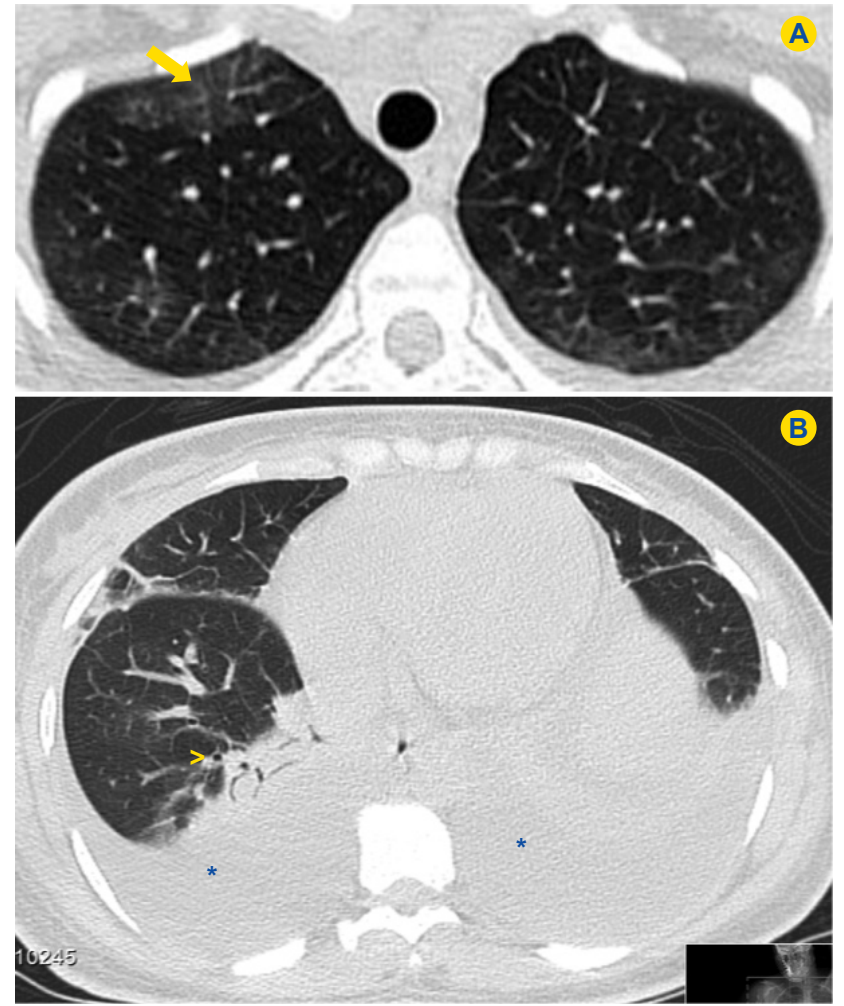

Figure 2 - Chest CT: densification with a mosaic pattern (arrow) in the lung parenchyma, predominantly in the upper lobes (A), and moderate bilateral pleural effusion (asterisk), conditioning passive atelectasis of the lower lobes (arrow head) (B)

adult respiratory distress and diffuse alveolar hemorrhage, are rare. $4,6,7$ When present, the most frequent respiratory symptoms are cough, pleuritic chest pain and mild dyspnea. Pleuritis is the most common pulmonary manifestation, and can be present in up to $53 \%$ of patients. ${ }^{6}$ Regarding pneumonitis, and according to the main studies (Table 2), it affects from $1.9 \%$ up to $27 \%$ of patients. ${ }^{3,6-13}$ This variability may reflect the sample size, the follow-up duration and the distinct demographic characteristics. Described in $27 \%$ of the reported cases by Pouchot et al, pulmonary infiltrates are transient, usually associated to pleural effusion, and are frequently located in the lower or upper lobes, as observed in our patient. ${ }^{6} \mathrm{~A}$ longer period of follow-up, with an average of 72 months, can explain a higher frequency of pulmonary involvement in this Canadian study. ${ }^{6}$ Furthermore, pneumonitis can be the initial form of this

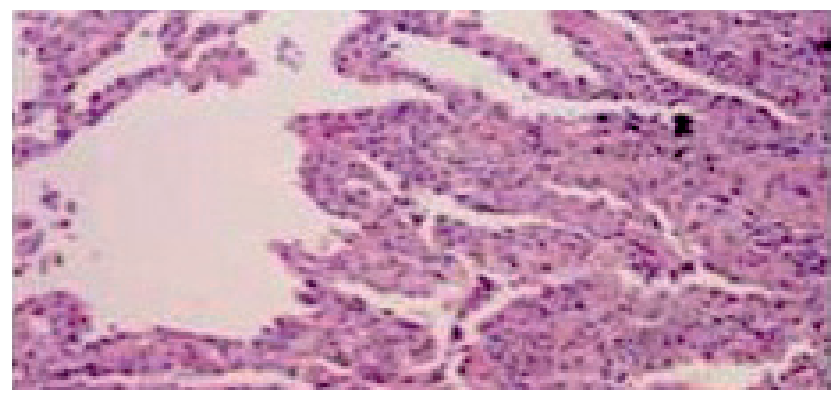

Figure 3 - Lung biopsy- lung tissue with inflammation, pneumocytes hyperplasia and fibrosis 
Table 1 - Analytical parameters evolution

\begin{tabular}{|c|c|c|c|c|c|c|}
\hline & $18 / 2$ & $21 / 2$ & $2 / 3$ & $13 / 3$ & $26 / 3$ & $23 / 5$ \\
\hline $\mathrm{Hb}(\mathrm{g} / \mathrm{dL})$ & 10.4 & 9.2 & 8.1 & 6.6 & 9.6 & 12.4 \\
\hline Leukocytes (cel/L) & 25510 & 22240 & 16760 & 7800 & 12520 & 7930 \\
\hline Neutrophils (\%) & 88.2 & 92.2 & 83.5 & 78.3 & 70.7 & 67.4 \\
\hline ESR (mm/h) & & & & 105 & 104 & 12 \\
\hline Ferritin (ng/mL) & & 2861.7 & 57480.3 & 35318.4 & 9371.6 & 557.1 \\
\hline Creatinine (mg/dL) & & 0.52 & 0.31 & 0.4 & 0.47 & 0.6 \\
\hline AST/ALT (U/L) & $63 / 59$ & & $/ 100$ & $130 / 117$ & $41 / 36$ & $17 / 29$ \\
\hline LDH (U/L) & 869 & 1328 & 1407 & 1701 & 830 & \\
\hline CRP (mg/dL) & 25.3 & 31.3 & 30,7 & 18 & 3.89 & $<0.04$ \\
\hline
\end{tabular}

$\mathrm{Hb}$ : haemoglobin; ESR: erythrocyte sedimentation rate; AST: aspartate aminotransferase; ALT: alanine aminotransferase; LDH: lactate dehydrogenase; CRP: C-reactive protein

Table 2 - Pulmonary involvement in AOSD series

\begin{tabular}{|c|c|c|c|c|}
\hline Study & $\mathbf{n}$ & Pleuritis (n/\%) & Pneumonitis (n / \%) & Source; Notes \\
\hline Reginato, $1987^{8}$ & 23 & $5 \% / 21.7 \%$ & $2 \% / 8.7 \%$ & USA \\
\hline Ohta, $1990^{9}$ & 90 & $11 \% / 12.2 \%$ & $5 \% / 5.6 \%$ & Japan \\
\hline Pouchot, $1991^{6}$ & 62 & $33 \% / 53 \%$ & $17 \% / 27 \%$ & $\begin{array}{l}\text { Canada; } 1 \text { case of interstitial pneumonitis progressed to } \\
\text { ARDS }\end{array}$ \\
\hline Zeng, $2009^{4}$ & 61 & $11 \% / 18 \%$ & $7 \% / 11.5 \%$ & $\begin{array}{l}\text { China; pleurisy and pneumonia associated with worse } \\
\text { prognosis }\end{array}$ \\
\hline Cagatay, $2009^{10}$ & 84 & $8 \% / 9.5 \%$ & $3 \% / 3.6 \%$ & Turkey \\
\hline Riera, $2011^{11}$ & 41 & $6 \% / 14.6 \%$ & $2 \% / 4.9 \%$ & Spain \\
\hline Chen, $2012^{12}$ & 61 & $7 \% / 11.5 \%$ & $3 \% / 4.9 \%$ & China \\
\hline Baxevanos, $2012^{7}$ & 22 & - & $1 \% / 4,5 \%$ & Greece; 1 case of fatal ARDS \\
\hline Kim, $2012^{13}$ & 54 & $11 \% / 20.4 \%$ & $1 \% / 1.9 \%$ & Korea \\
\hline
\end{tabular}

$\mathrm{n}$ : number of patients; ARDS: acute respiratory distress syndrome; USA: United States of America

disease, associated to fever, leukocytosis with neutrophilia and elevated acute phase proteins, leading to consider the diagnosis of pneumonia. ${ }^{14}$

Actually, pulmonary involvement may be more frequent than currently thought. Indeed, a clinical case described by Zhao and colleagues, where no signs or symptoms of lung involvement were documented, revealed a slight lung inflammatory infiltrate at the time of autopsy, suggesting that transient inflammatory infiltrates in the lung parenchyma may occur asymptomatically and may not be detected in the chest radiograph. ${ }^{15}$ Histopathological findings, previously described in the literature, like nonspecific interstitial fibrosis, acute alveolitis with thickening of the alveolar walls, hyperplasia of type II pneumocytes, hyaline membrane formation, and lymphocytic infiltrate, include those found in our patient. Angiitis has not been described. ${ }^{3,15}$

Generally, pulmonary involvement has a favorable clinical evolution, but studies on prognosis of these patients are limited. ${ }^{3}$ A retrospective review suggested that interstitial pneumonia and pleurisy, as well as high levels of ferritin and persistent fever after three days of treatment with prednisone $1 \mathrm{mg} / \mathrm{kg} /$ day were factors of less favorable prognostic. ${ }^{4}$ In this case report there was a complete resolution of the lung involvement after initiation of corticosteroid therapy at the dose of $1 \mathrm{mg} / \mathrm{kg} / \mathrm{day}$ of prednisolone, in accordance with current clinical practice.
The clinical report described highlights AOSD pulmonary involvement in the form of pneumonitis, which may be more frequent than we currently expect given its, probably often, silent course. Furthermore, although usually associated to a favorable clinical progression, pneumonitis has been reported as a negative prognostic factor, requiring appropriate diagnosis, with exclusion of potentially fatal pulmonary events, and therapeutics.

\section{PROTECTION OF HUMANS AND ANIMALS}

The authors declare that the procedures were followed according to the regulations established by the Clinical Research and Ethics Committee and to the Helsinki Declaration of the World Medical Association.

\section{DATA CONFIDENTIALITY}

The authors declare having followed the protocols in use at their working center regarding patients' data publication.

\section{CONFLICTS OF INTEREST}

All authors report no conflict of interest.

\section{FUNDING SOURCES}

This research received no specific grant from any funding agency in the public, commercial, or not-for-profit sectors. 


\section{REFERENCES}

1. Bywaters EG. Still's disease in the adult. Ann Rheum Dis. 1971;30:12133.

2. Efthimiou P, Paik PK, Bielory L. Diagnosis and management of adult onset Still's disease. Ann Rheum Dis. 2006;65:564-72.

3. Cheema GS, Quismorio FP. Pulmonary involvement in adult-onset Still's disease. Curr Opin Pulm Med. 1999;5:305-9.

4. Zeng $T$, Zou YQ, Wu MF, Yang CD. Clinical features and prognosis of adult-onset still's disease: 61 cases from China. J Rheumatol. 2009;36:1026-31.

5. Yamaguchi M, Ohta A, Tsunematsu T, Kasukawa R, Mizushima $Y$, Kashiwagi $\mathrm{H}$, et al. Preliminary criteria for classification of adult Still's disease. J Rheumatol. 1992;19:424-30.

6. Pouchot J, Sampalis JS, Beaudet F, Carette S, Décary F, SalusinskySternbach M, et al. Adult Still's disease: manifestations, disease course, and outcome in 62 patients. Medicine. 1991;70:118-36.

7. Baxevanos G, Tzimas T, Pappas G, Akritidis N. A series of 22 patients with adult-onset Still's disease presenting with fever of unknown origin. A difficult diagnosis? Clin Rheumatol. 2012;31:49-53.

8. Reginato AJ, Schumacher HR, Baker DG, O'Connor CR, Ferreiros J. Adult onset Still's disease: experience in 23 patients and literature review with emphasis on organ failure. Semin Arthritis Rheum. 1987;17:39-57.

9. Ohta A, Yamaguchi M, Tsunematsu T, Kasukawa R, Mizushima H Kashiwagi $\mathrm{H}$, et al. Adult Still's disease: a multicenter survey of Japanese patients. J Rheumatol. 1990;17:1058-63.

10. Cagatay $Y$, Gul A, Cagatay A, Kamali S, Karadeniz A, Inanc M, et al. Adult-onset Still's disease. Int J Clin Pract. 2009;63:1050-5.

11. Riera E, Olivé A, Narváez J, Holgado S, Santo P, Mateo L, et al Adult onset Still's disease: review of 41 cases. Clin Exp Rheumatol. 2011;29:331-6.

12. Chen PD, Yu SL, Chen S, Weng XH. Retrospective study of 61 patients with adult-onset Still's disease admitted with fever of unknown origin in China. Clin Rheumatol. 2012;31:175-81.

13. Kim HA, Sung JM, Suh CH. Therapeutic responses and prognosis in adult-onset Still's disease. Rheumatol Int. 2012;32:1291-8.

14. Nie H, Ding X, Huang Y, Hu S. Adult-onset Still's disease misdiagnosed as pneumonia: two case reports. Acta Reumatol Port. 2011;36:413-7.

15. Zhao DB, Dai SM, Liu XP, Xu H. Interstitial inflammation in visceral organs is a pathologic feature of adult-onset Still's disease. Rheumatol Int. 2011;31:923-7.
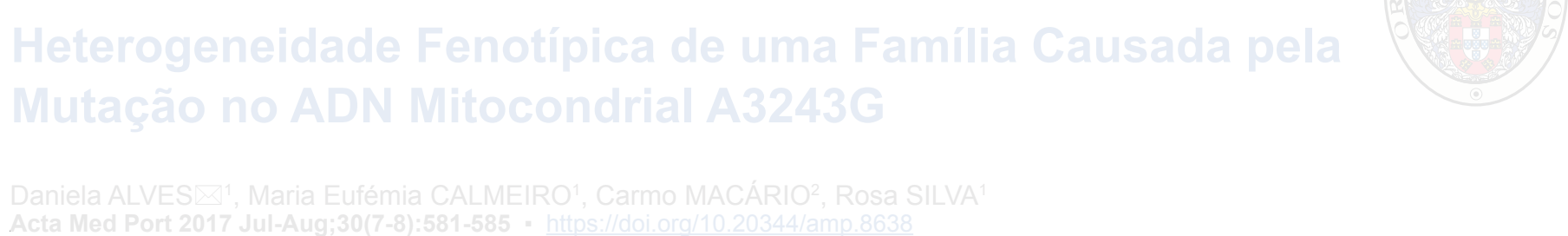